\title{
Use of Soil-Map Delineations to Improve (Co-)Kriging of Point Data on Moisture Deficits*
}

\author{
A. STEIN, M. HOOGERWERF and J. BOUMA \\ Department of Soil Science and Geology, Agricultural University, P.O. Box 37,6700 AA \\ Wageningen (The Netherlands)
}

(Received January 18, 1988; accepted after revision July 12, 1988)

\begin{abstract}
Stein, A., Hoogerwerf, M. and Bouma, J., 1988. Use of soil-map delineations to improve (co-) kriging of point data on moisture deficits. Geoderma, 43: 163-177.

Predictions of 30-year average moisture deficits (MD30) were carried out by means of kriging and co-kriging, using simulations for 500 point observations in an area of 404 ha of sandy soils in The Netherlands. From the above point observations 100 points were selected at random to function as an independent test set. Attention was focused on improving the precision of kriged and co-kriged MD30-maps, as characterized by two error measures, the mean variance of the prediction error and the mean squared error of predictions. To do so the survey area was stratified by means of soil-map delineations according to soil type and water-table classes based on the groundwater table. In unstratified maps the standard deviation of the prediction error largely depends on the observation pattern. Stratification resulted in an increase of precision of predictions in strata with low MD30 variability and an apparent decrease in strata with high MD30 variability. Major soil-map delineations, as distinguished by a soil survey, had significantly different internal variability. Use of co-kriging resulted in an average increase of precision of MD30-maps of about $10 \%$. This study illustrates the use of available soil-survey information for stratifying a survey area so as to enhance precision of predictions when using kriging and co-kriging of point data.
\end{abstract}

\section{INTRODUCTION}

Kriging and co-kriging are becoming well established statistical prediction techniques to produce predictive soil maps (McBratney and Webster, 1983; Yates and Warrick, 1987). The ready availability of user-friendly software and the fact that the techniques are well founded and the results can be clearly interpreted have made it easy and attractive to apply them. Obviously, the quality of the results obtained is directly related to the quality and the varia-

\footnotetext{
*Contribution from the Department of Soil Science and Geology of the Agricultural University Wageningen, The Netherlands, and the Netherlands Soil Survey Institute, P.O. Box 37, 6700 AA Wageningen, The Netherlands.
} 
bility of the basic data being used and to the selected patterns of observations. These can be regular grids with various configurations or patterns with random components. Preselected grids usually do not take into account geological or pedological differences which form the basis for different delineations on the soil map.

A basic question may be raised as to whether soil-map delineations are of value in creating predictive soil maps. Much variation is likely to be found when a sampling grid is placed over an area with contrasting soil types using (co-) kriging. Webster (1985) recognizes this problem by stating: "The sampling scheme was deliberately designed to distinguish major geological formations in the first stage, since it would have been foolish to have ignored such obvious features." Implicitly it may be postulated therefore that sampling within major soil delineations would result in less overall variability as compared with a situation in which the sampling grid covers several delineations. So far, no soil-survey research has been reported covering this particular aspect. This is surprising because if indeed predictions would be more precise when applied within major soil-map delineations as a form of stratified sampling, a new use of existing soil maps would be introduced. The purpose of this study was to test the feasibility of using sample stratification in creating predictive soil maps on the basis of soil-map delineations.

\section{MATERIALS AND METHODS}

\section{The survey area}

In 1985 a detailed soil survey was made in the Mander area in the eastern Netherlands by the Dutch Soil Survey Institute (Stiboka) to study the influence of groundwater extraction on the production of grassland (Wösten et al., 1987). The Mander area consists of sandy soils, which are classified as Haplaquods, Humaquepts and Plaggepts (Wösten et al., 1987). Fluctuations of the groundwater table $(\mathrm{Gt})$ are routinely characterized by Dutch soil surveyors in terms of mean highest (MHW) and mean lowest (MLW) levels (Van der Sluys and De Gruijter, 1985; Fig. 1b, Table I). In the Mander area water-table levels were recorded from 1953 to 1955 and in 1985 . Simulated values with a 10 -day interval were obtained by means of other data in the intermediate period. The groundwater classes in the area are based on the MHW and the MLW as indicated in Table I. Lowering of water tables results in a change in production, e.g. of grassland, due to lower fluxes of water from the water table to the root zone. Farmers are financially compensated for production losses by municipal water companies. In the 404 ha study area, 500 soil borings were made. Hydraulic conductivity and moisture retention data for major soil horizons were measured and averaged as described by Wösten et al. (1985, 1987). The computer simulation model LAMOS (Bouma et al., 1980a, b) was used to obtain 

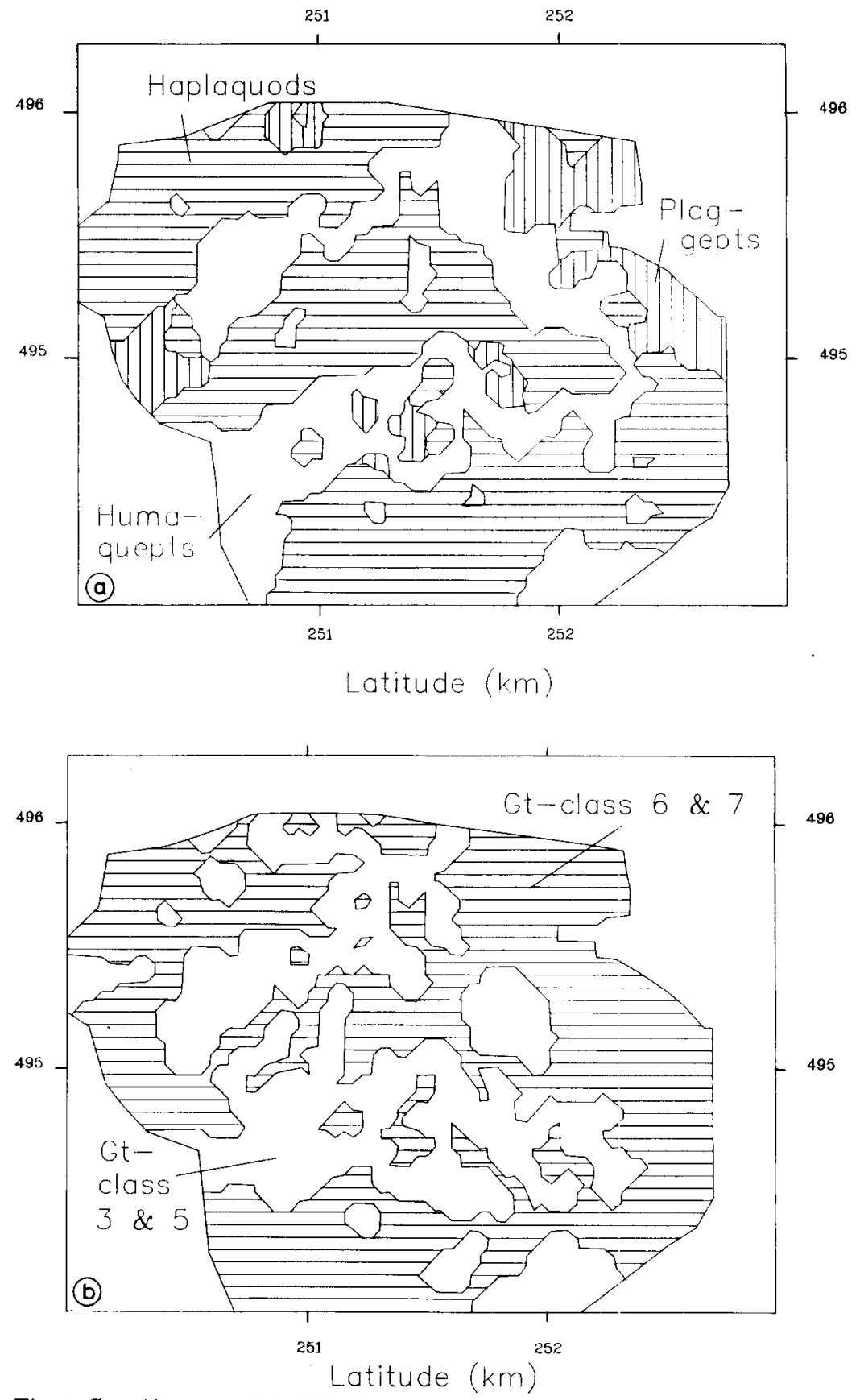

Fig. 1. Stratification of the Mander area according to Humaquepts, Haplaquods and Plaggepts (a) and according to Gt-classes $3+5$ and $6+7$ (b). 
TABLE I

Groundwater classes and mean highest and mean lowest groundwater levels, occurring in the Mander area

\begin{tabular}{lll}
\hline Class & \multicolumn{2}{l}{ Groundwater level $(\mathrm{cm})$} \\
\cline { 2 - 3 } & mean highest & mean lowest \\
\hline 3 & $<40$ & $80-120$ \\
5 & $<40$ & $>120$ \\
6 & $40-80$ & $>120$ \\
7 & $>80$ & $>120$ \\
\hline
\end{tabular}

the necessary quantitative expressions for the moisture deficits and the associated yields. Simulation calculations were made for each boring location for a 30 -year period. For this study attention was focused on the 30 -year average value for the moisture deficit (MD30). To evaluate the predictions by kriging and co-kriging, 100 borings were selected at random from the data set to serve as a test set. Predictions were made for the test set using the calculated values for the moisture deficits of the remaining 400 borings (see: Statistical procedures). Attention was focused on the average precision obtained for the 100 test locations. The two Gt-class strata contained 141 and 258 borings and the three soil strata contained 121 borings in Humaquepts, 227 in Haplaquods and

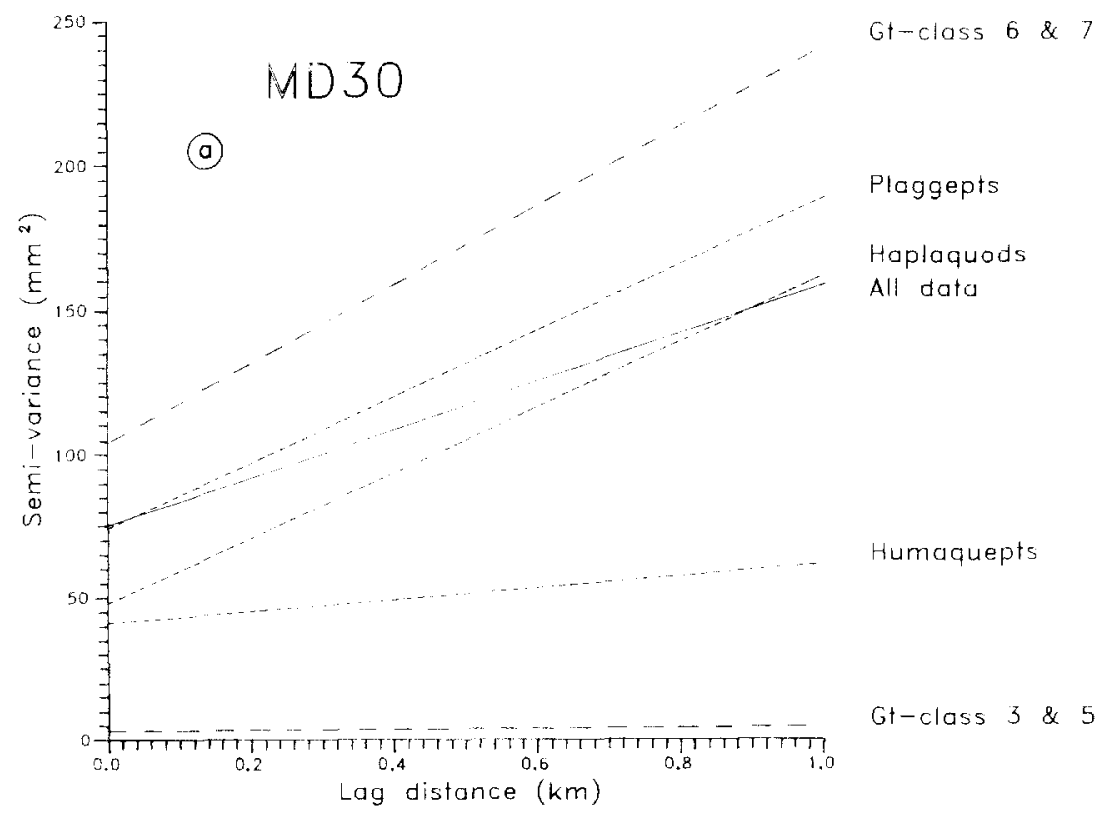




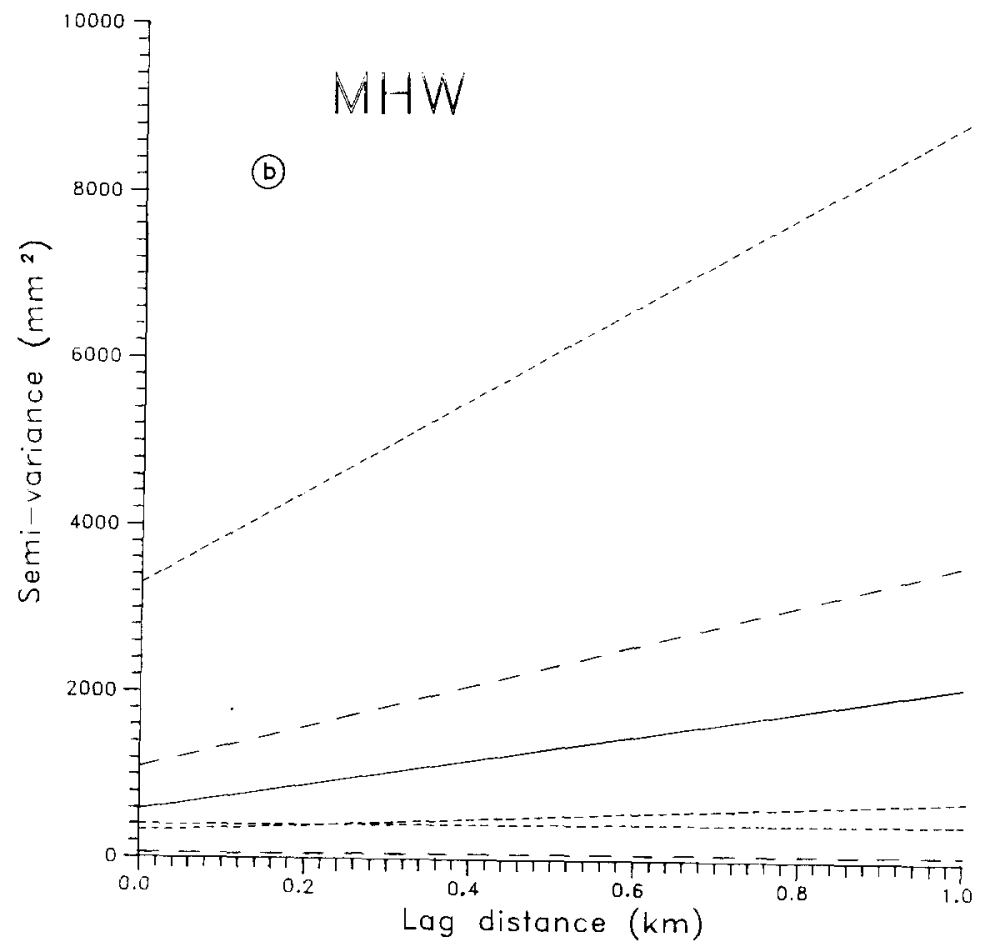

Plaggepts

Gt-class 6 \& 7

All data

Haplaquods

Humaquepts

Gt-class 3 \& 5

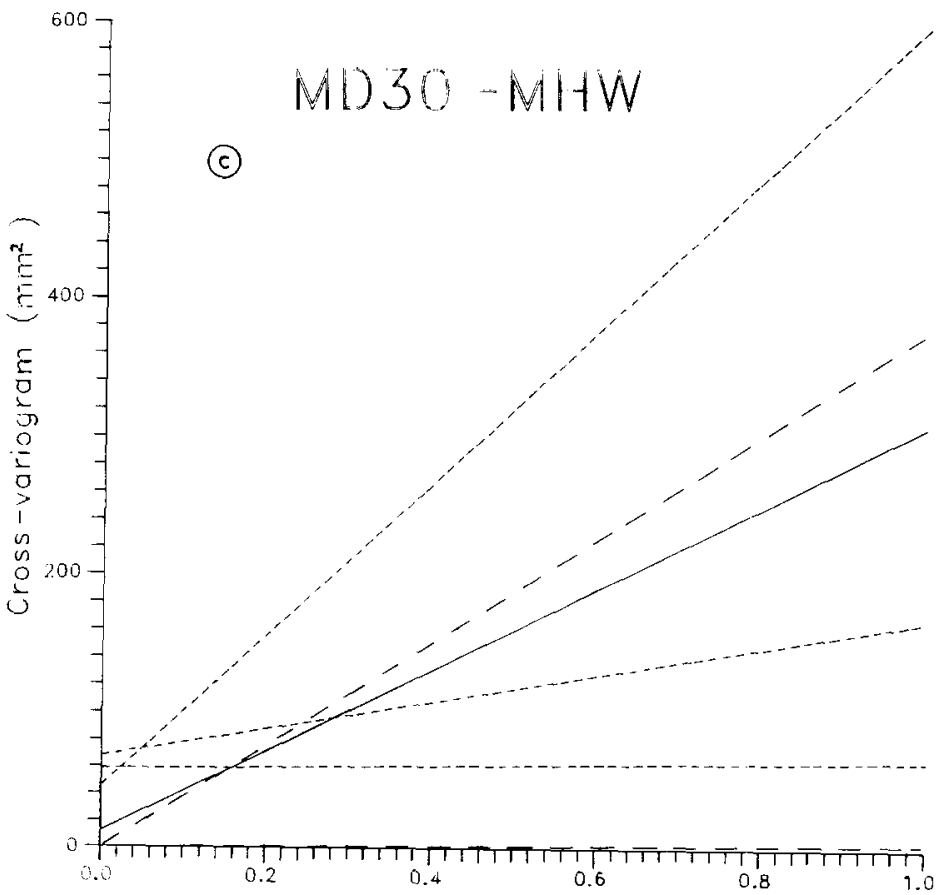

Plaggepts

Gt-class 6 \& 7

All data

Haplaquods

Humaquepts

Gt-class 3 \& 5

Fig. 2. Semi-variograms for MD30 (2a) and MHW (2b) and cross-variograms for MD30 with MHW (2c) according to different strata. 
Number of observations of MD30 and the correlation coefficient of MD30 with MHW in different strata

\begin{tabular}{lcl}
\hline & Number & $\begin{array}{l}\text { Corr. } \\
\text { coeff. }\end{array}$ \\
\hline All data & 399 & .587 \\
Humaquepts & 121 & .387 \\
Haplaquods & 227 & .453 \\
Plaggepts & 51 & .604 \\
Gt-class $3+5$ & 141 & .158 \\
Gt-class $6+7$ & 258 & .405 \\
\hline
\end{tabular}

51 in Plaggepts, respectively (Table II). The two Gt-class strata contained 47 and 53 test borings and the three soil strata contained 42 test borings in $\mathrm{Hu}$ maquepts, 47 in Haplaquods and 11 in Plaggepts, respectively.

\section{Statistical procedures}

In this study the statistical prediction techniques kriging and co-kriging are used to provide predictors for the values of the so-called predictand (MD30) in the test points. These predictors have certain favourable properties: they are unbiased, they depend linearly on the observations and they have minimal variance of the prediction error (Vauclin et al., 1983). Apart from the prediction itself, the variance of the prediction error is calculated, sometimes referred to as the 'kriging error' (see, for instance, Journel and Huijbregts, 1978), which gives an indication of the performance of the predictor. In this study we assumed that soil variables are isotropic and obey the intrinsic hypothesis within soil strata. Thus use was made of semi- and cross-variograms. In co-kriging, the variable MHW was used as a co-variable, because of its high correlation with MD30 (correlation coefficient .587) and its clear spatial correlation (Fig. $2 c)$. For the prediction of MD30 in any point of the test set by kriging eight neighbouring observations of MD30 were used. In co-kriging the observations of the co-variable $\mathrm{MHW}$ in the prediction points concerned was used as well, to give more precise results than when it is left out (Stein et al., 1988). The predictions were afterwards compared with the observed values in the test set.

Throughout this study stochastic variables are denoted boldface to distinguish between a variable and the value which might be assigned to this variable. Two measures were used to obtain insight in the performance of the predictors, the Mean Variance of the Prediction Error (MVPE) and the Mean of Squared Errors of Predictions (MSEP). They are defined as follows: 
$\operatorname{MVPE}=(1 / n) \sum_{i=1}^{n} \operatorname{Var}\left(\boldsymbol{t}_{i}-\boldsymbol{y}_{0 i}\right)$

$\operatorname{MSEP}=(1 / n) \sum_{i=1}^{n}\left(t_{i}-y_{i}\right)^{2}$

where $\boldsymbol{t}_{i}=$ the (stochastic) predictor provided by kriging or co-kriging in the $i$ th test point; $\boldsymbol{y}_{0 i}=$ the variable $\boldsymbol{y}$ when a prediction in the $i$ th test point is being carried out; $t_{i}=$ the prediction in the $i$ th test point; $y_{i}=$ the observation in the $i$ th test point; $n=$ the number of observations in the test set.

As we have for a single prediction point the well-known relation

$E\left(t-t_{0}\right)^{2}=\operatorname{Var}\left(t-y_{0}\right)+\left\{E\left(t-y_{0}\right)\right\}^{2}$

and $E\left(\boldsymbol{t}-\boldsymbol{y}_{0}\right)^{2}$ is estimated in the mean by:

$(1 / n) \sum_{i=1}^{n}\left(t_{i}-y_{i}\right)^{2}$

averaging over the test set yields the equation:

MSEP $=$ MVPE + bias

where the bias is due to model deficiency. This gives the connection between the MSEP and the MVPE. Taking square roots yields a comparison between the measures in units of the predictand.

Stratification can be expressed in terms of the partitioning of an area. After stratification the total area $A$ is partitioned into, say, $p$ disjoint non empty subareas or strata, $A_{1}, A_{2}, \ldots, A_{p}$, with $A_{1} \cup A_{2} \cup \ldots \cup A_{p}=A, A_{i} \cap A_{j}=\phi$ for $i \neq j$ and $A_{i} \neq \phi$ for all $i$. On each stratum $A_{i}$ the $k$ soil properties are being described by $k$ regionalized variables $\boldsymbol{y}_{i}^{(j)}(x), j=1, \ldots, k$, depending on the location vector $x$, here in two dimensions. Within each stratum every variable is considered to follow the intrinsic hypothesis, that is for all $i$ and for all $j$ :

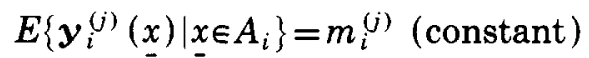

$\operatorname{Var}\left\{\boldsymbol{y}_{i}^{(j)}(\underline{x}+\underline{h})-\boldsymbol{y}_{i}^{(j)}(\underline{x}) \mid \underline{x}+\underline{h} \in A_{i}\right.$ and $\left.\underline{x} \in A_{i}\right\}<\infty$

The isotropy of the variables implies that the variance depends solely on $|h|$, the length of the vector $h$, and not on its direction. Predictions in the entire region have to be carried out with respect to the stratified area; that is for every point in the test set the predictor has to be entirely based on observations belonging to the same stratum.

Stratification of the region was based upon groundwater classes (Fig. 1a) and upon soil types (Fig. $1 \mathrm{~b}$ ), which are routinely determined during soil survey. Every observation was assigned to one particular stratum. In stratification according to groundwater classes, classes 3 and 5 were combined as well as 
classes 6 and 7 to have sufficient observations per stratum to yield reliable estimates for semi- and cross-variograms.

In order to investigate the significance of the encountered differences, a test was developed, which incorporates the spatial dependence structure of the variables within the distinguished strata (see Appendix). As the sample sizes for the individual strata were too large to be handled by personal computers, random selections of 50 observations per stratum were used,

For every stratum the appropriate variograms were estimated and used in the predictions. In general, the MVPE and the MSEP were expected to change after stratification had been carried out. As the variance of the prediction error depends on the pattern of the observations, the MVPE is likely to increase when stratification is being carried out, because the observation points to be used in the predictions in general are located further away from the point where an MD30 prediction is being made. On the other hand, as the determination of the variograms is also based upon individual strata, a general decrease of the MVPE may also be expected as well as a decrease within areas with low variability. Due to the fact that observations from outside the predefined strata no longer were used, the MSEP was expected to decrease after stratification.

For the semi- and the cross-variograms a linear model without sill, $g(h)=a+b h$, was fitted by means of weighted least squares; weights were based upon the number of pairs of points in a distance class (Table III, Fig. 2). Predictions are based on the eight nearest observation points of MD30, and in the case of co-kriging also on the eight nearest observation points of MHW.

Statistical calculations were carried out with the computer package LANDSTAT on personal computers at the Agricultural University Wageningen; results were displayed with the computer package SURFER, which is a release of Golden Software, Inc., Golden, Colorado.

\section{TABLE III}

Estimated coefficients of a linear model without sill for semi- and cross-variograms for MD30 and MHW in different strata (see also Fig. 2)

\begin{tabular}{|c|c|c|c|c|c|c|}
\hline & \multicolumn{2}{|c|}{ MD30 } & \multicolumn{2}{|c|}{ MHW } & \multicolumn{2}{|c|}{ MD30-MHW } \\
\hline & a & $\mathrm{b}$ & a & $b$ & a & b \\
\hline All data & 75 & 84 & 587 & 1520 & 12 & 295 \\
\hline Humaquepts & 41 & 21 & 396 & 60 & 58 & 7 \\
\hline Haplaquods & 48 & 114 & 323 & 411 & 68 & 98 \\
\hline Plaggepts & 74 & 115 & 3300 & 5550 & 46 & 549 \\
\hline Gt-class $3+5$ & 3 & 2 & 53 & 20 & 0 & 4 \\
\hline Gt-class $6+7$ & 104 & 137 & 1100 & 2460 & 0 & 375 \\
\hline
\end{tabular}


RESULTS

\section{Stratification}

The strata differ with respect to moisture deficits as estimations for the mean values and standard deviations around the mean within the strata are different (Table IV). The calculated significance at the 0.001 level of all differences obtained (according to chi-squared testing) should however be interpreted with care, because the sampling scheme is based on well-known soillandscape relations, which implies that the estimators for means and standard deviations were necessarily biased.

The strata also differ according to the fitted variograms (Fig. 2) as intercept (the nugget effect) and slope differ between different strata. For instance, when comparing the stratum defined by Gt-class 3 and 5 with the stratum defined by Gt-class 6 and 7, the semi-variogram for MD30 has a lower intercept ( 3 and 104, respectively) and a less strong slope (2 and 137, respectively) (Fig. 2a). Differences among MD30 values within areas occupied by Humaquepts are relatively small. Increasing the sampling density in Humaquept areas has a minor effect on decreasing the standard deviation of the prediction error of MD30 predictions. Increasing the sampling density in Haplaquod and Plaggept areas, however, more strongly decreases the standard deviation of the prediction error of MD30 predictions (Fig. 2a).

The MVPE and the MSEP resulting from the predictions of MD30 for the test set are presented in Table $\mathrm{V}$ as averages for the entire test set and for the different strata. The MVPE decreases from 9.30 to 72.8 after stratification according to Gt-class and from 93.0 to 79.8 after stratification according to soil type. The MSEP decreases from 68.1 to 56.4 after stratification according to Gt-class and increases to 75.6 after stratification according to soil type. This clearly indicates that an overall increase of precision is obtained. Table $\mathrm{V}$ also

\section{TABLE IV}

Estimations for mean and standard deviation of the mean based on spatial structure of MD30 in the different strata

\begin{tabular}{lrl}
\hline & Mean & $\begin{array}{l}\text { S.d. of } \\
\text { the mean }\end{array}$ \\
\hline All data & 10.1 & 3.2 \\
Humaquepts & 9.9 & 3.4 \\
Haplaquods & 4.9 & 1.3 \\
Plaggepts & 25.1 & 5.5 \\
Gt-class 3+5 & 1.8 & 0.1 \\
Gt-class 6+7 & 16.3 & 4.5 \\
\hline
\end{tabular}




\section{TABLE V}

Results of the test that no significant differences exist between the strata

\begin{tabular}{lrll}
\hline & \multicolumn{1}{c}{$T$} & $\begin{array}{l}\text { Degrees } \\
\text { of freedom }\end{array}$ & Significance \\
\hline Between Gt-classes & 22.4 & 1 & $<0.001$ \\
Between soil types & 716.0 & 2 & $<0.001$ \\
Haplaquods-Humaquepts & 24.2 & 1 & $<0.001$ \\
Haplaquods-Plaggepts & 540.8 & 1 & $<0.001$ \\
Humaquepts-Plaggepts & 410.1 & 1 & $<0.001$ \\
\hline
\end{tabular}

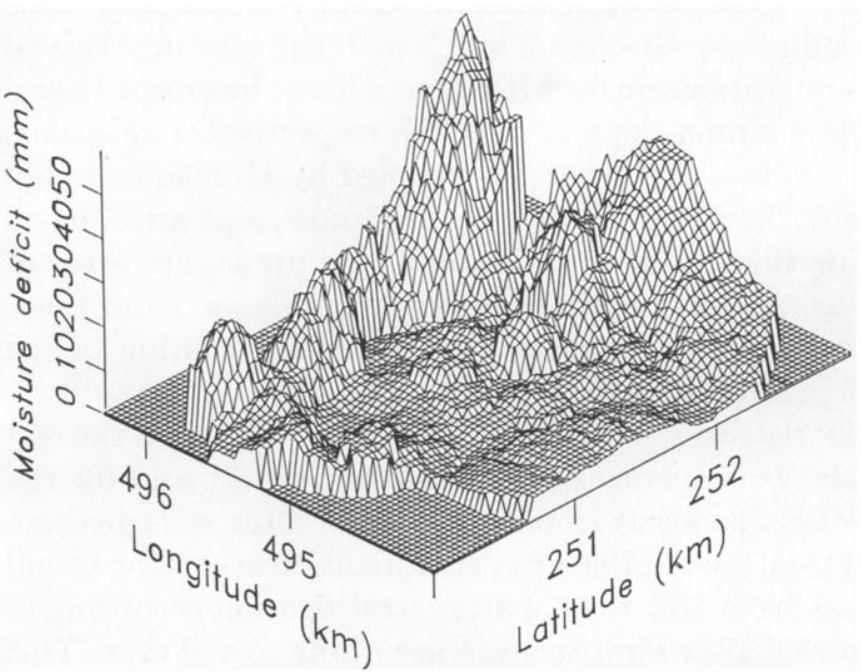

Fig. 3. Co-kriged MD30 map of the Mander area in a three-dimensional presentation. This map is of uniform precision, with decreasing precision only at the borders, as indicated by Fig. 4 .

indicates that separation of the two Gt-classes has been quite meaningful, because MVPE and MSEP values were very low for the relatively homogeneous Gt-class 3 and 5 and very high for the relatively heterogeneous Gt-class 6 and 7. This means that the two strata contain two different MD30 populations. Differences are also observed among the three soil strata. The MSEP value for Plaggepts is relatively high, due to the high mean value of MD30 within the Plaggept stratum.

By creating strata from a standard soil map, variability can be allocated to areas where it naturally belongs. When strata are ignored, average MVPE and MSEP values are obtained that mask the fact that variability is characteristically lower in certain strata and higher in others. 


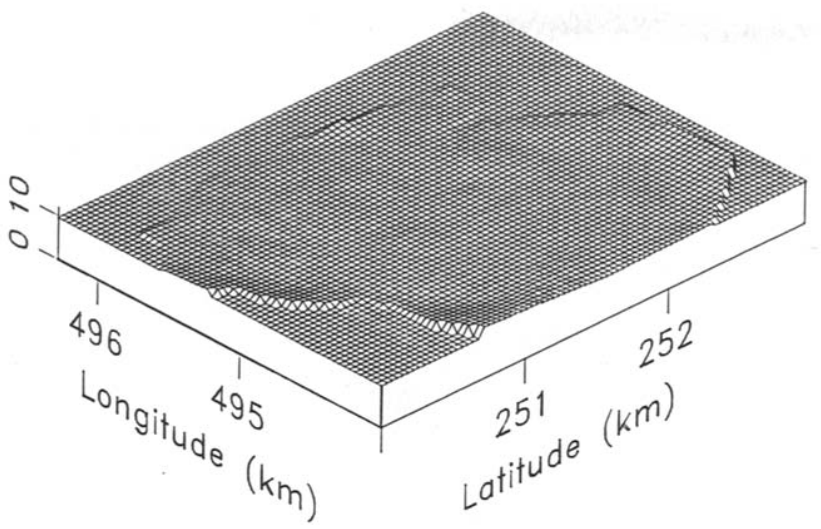

Fig. 4. Map of the standard deviation of the prediction error of the co-kriged MD30 map in a three-dimensional presentation.

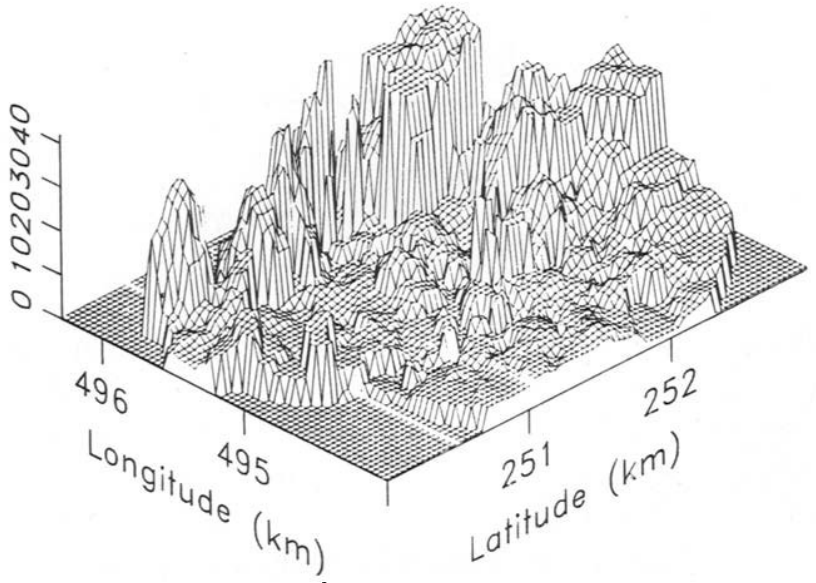

Fig. 5. Co-kriged MD30 map of the Mander area based on stratification according to soil type in a three-dimensional presentation. This map is not of uniform precision, as indicated by Fig. 6 .

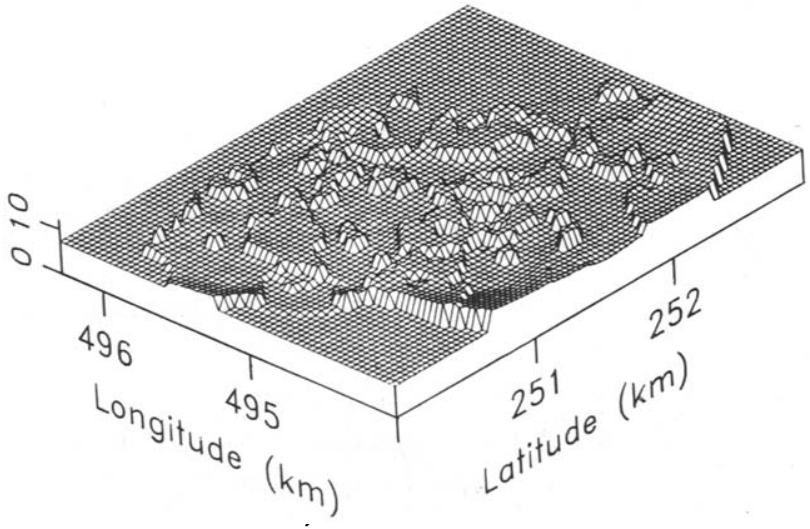

Fig. 6. Map of the standard deviation of the prediction error of the co-kriged MD30 map after stratification according to Soil type. Sharp boundaries exist between the different strata. The pattern is comparable with the pattern of soil types (Fig. 1b). 
The MVPE and MSEP values according to kriging and co-kriging for the region stratified according to soil type (soil-strat.) and groundwater classes (Gt-strat.); the values for the MVPE and the MSEP for the unstratified region as well as within different strata are included

\begin{tabular}{lcccc}
\hline & \multicolumn{3}{c}{ MVPE } & \multicolumn{2}{c}{ MSEP } \\
\cline { 2 - 3 } \cline { 5 - 6 } & kriging & co-krig. & kriging & co-krig. \\
\hline Unstrat. & 93.0 & 90.7 & 68.1 & 61.2 \\
Soil-strat. & 79.8 & 68.3 & 75.6 & 70.0 \\
Humaquept & 101.3 & 97.3 & 48.6 & 48.2 \\
Haplaquods & 67.3 & 48.5 & 53.6 & 57.3 \\
Plaggepts & 51.5 & 41.9 & 273.0 & 207.6 \\
Gt-strat. & 72.8 & 72.0 & 56.4 & 50.2 \\
Gt-class 3+5 & 3.7 & 3.7 & 4.1 & 4.2 \\
Gt-class 6+7 & 134.2 & 132.6 & 102.8 & 91.0 \\
\hline
\end{tabular}

\section{Co-kriging}

Co-kriging generally resulted in more precise predictions than did kriging (Table V). The increases in precision ranged from 0 to 25\%. Some MSEP values were larger for co-kriging than for kriging. This may be due to numerical instability (rounding), caused by the fairly small size of the test set for the individual strata. The combination of stratification and co-kriging was nearly always succesful, in that the MSEP decreased from 61.2 to 50.2 after stratification according to Gt-class but increased to 70.0 after stratification according to soil type, probably due to the fact that observation points used in the predictions are located further away. The MVPE value decreased from 90.7 to 72.0 after stratification according to Gt-class and to 68.3 after stratification according to soil type.

When one creates a predictive MD30 map, the average standard deviation of the prediction error will be 9.5 without stratification and will range from 7.2 to 10.1 in the case of stratification according to soil type. The predictive MD30 soil map obtained without stratification is of more or less uniform precision (Figs. 3 and 4). As is well known, precision only decreases in the parts of the area which are less densely sampled, such as near the border of the area. A predictive soil map obtained with stratification, however, does not show uniform precision (Figs. 5 and 6 ). Strata showing high spatial variability are the less precise parts of predictive soil maps as compared with the strata which show low spatial variability. 


\section{DISCUSSION}

There are interesting consequences for soil survey by analyzing the above results. When a specific degree of accuracy of predictions is required it is feasible to decrease the number of observations in strata showing relatively low variability and to increase the number of observations in strata showing relatively high variability. The variograms (Fig. 2) allow a quantitative analysis which relates the accuracy of predictions obtained to distance between observation points. In this study, an existing soil map was used for stratification purposes. Thus, available soil survey expertise was used in an innovative manner. In many countries systematic soil surveys are completed. One possible future activity would be to determine the internal variability of existing major land units so as to allow statistically founded quantitative predictions of relevant land qualities rather than qualitative estimates based on the properties of "representative" profiles. This study has demonstrated that existing mapping criteria can be relevant to define effective strata for (geo-)statistical analysis.

When no soil maps are available, it would be advisable to distinguish major land units by means of common soil survey techniques, including remote sensing, and to focus further variability studies on these units rather than on the landscape as a whole with random observations. Continued research is needed to determine which characteristics are most promising for use in stratification and by which criteria they are to be selected. One of the criteria is that the number of data points available to estimate the variogram must be large enough to give reliable estimates. Stratification therefore has to be carried out on the basis of units containing at least 30 to 40 data points. As indicated in Table VI, stratification according to the two Gt-classes was slightly more succesful than stratification according to the three soil types. Different results are likely to be obtained if different land units and land qualities are considered.

Application of co-kriging gives more precise results than ordinary kriging. In this study use could be made of a co-variable (MHW) which was rather highly correlated with the predictand (MD30). Search for such variables is of crucial importance in succesful application of co-kriging.

Both stratification and co-kriging are valuable in geographic information systems, becoming common tools in soil science. Maximizing the accuracy of predictions and, at minimum cost, dealing with variability aspects as a function of different land units is an important task for soil scientists in the future.

\section{ACKNOWLEDGMENTS}

We want to acknowledge the assistance of G. Stoffelsen from the Netherlands Soil Survey Institute for collecting the data and the helpful comments of L.C.A. Corsten from the Department of Mathematics of the Agricultural 
University and of A.K. Bregt and J.J. de Gruijter from the Netherlands Soil Survey Institute.

\section{APPENDIX}

A test was developed to investigate the significance of the differences in mean values between strata when the observations of a regionalized variable are (spatially) related. Suppose $p$ strata are investigated, from every stratum it is known that the spatial dependency structure is given by the correlation function $c_{i}(r)$ for $r \geq 0, i=1, \ldots, p$. As an estimator for the mean and the variance within the $i$ th stratum we have:

$\hat{\mu}_{i}=\frac{1_{n}^{\prime} C_{i}^{-1} y}{1_{n}^{\prime} C_{i}^{-1} 1_{n}}=\frac{1_{n}^{\prime} n G_{i}^{-1} y}{1_{n}^{\prime} G_{i}^{-1} 1_{n}}=\frac{1_{n}^{\prime} \Gamma_{i}^{-1} y}{1_{n}^{\prime} \Gamma_{i}^{-1} 1_{n}}$

where the matrix $C_{i}$ contains values of the covariance function within the $i$ th stratum, the matrix $G_{i}$ contains values of the semi-variogram in the $i$ th stratum and the matrix $\Gamma_{i}$ contains values of the generalized covariance function between observations in the ith stratum. Of course, $C_{i}, G_{i}$ and $\Gamma_{i}$ depend also on the variable under study. The variance of the mean is equal to:

$\operatorname{Var}\left(\hat{\underline{\mu}}_{i}\right)=\left(1_{n}^{\prime} C_{i}^{-1} 1_{n}\right)^{-1}=-\left(1_{n}^{\prime} G_{i}^{-1} 1_{n}\right)^{-1}=-\left(1_{n}^{\prime} \Gamma_{i}^{-1} 1_{n}\right)^{-1}=: \frac{1}{g_{i}}$

The null hypothesis $\mathrm{H}_{0}$ that no differences exist between the different strata and the alternative hypothesis $\mathrm{H}_{1}$ can be formulated as:

$\mathrm{H}_{0}: \quad \mu_{1}=\mu_{2}=\ldots=\mu_{p}$

$\mathrm{H}_{1}$ : at least one $\mu_{j}$ differs from the other $\mu_{i}$ 's, $i \neq j$

When the spatial structure is known, this hypothesis is tested with the test statistic

$T=\sum_{i=1}^{p} g_{i} \hat{\underline{\mu}} m_{i}^{2}-\left(\sum_{i=1}^{p} g_{i} \underline{\underline{\mu}}_{i}\right)^{2} /\left(\sum_{i=1}^{p} g_{i}\right)$

which has under $\mathrm{H}_{0}$ a chi-squared distribution with $p-1$ degrees of freedom. Of course, in practical studies the spatial structure has to be estimated from the data. As the test value will only slightly change, the same chi-square distribution was being used.

\section{REFERENCES}

Bouma, J., De Laat, P.J.M., Awater, R.H.C.M., Van Heesen, H.C., Van Holst, A.F. and Van de Nes, Th.J., 1980a. Use of soil survey data in a model for simulating regional soil moisture regimes. Soil Sci. Soc. Am. J., 44 (4): 808-814.

Bouma, J., De Laat, P.J.M., Van Holst, A.F. and Van de Nes, Th.J., 1980b. Predicting the effects of changing water-table levels and associated soil moisture regimes for soil survey interpretations. Soil Sci. Soc. Am. J., 44(4): 797-802.

Journel, A.G. and Huijbregts, Chr. J., 1978. Mining Geostatistics. Academic Press, New York, N.Y.

McBratney, A.B. and Webster, R., 1983. Optimal interpolation and isarithmic mapping of soil properties, V. Coregionalization and multiple sampling strategy. J. Soil Sci., 34: 137-162. 
Stein, A., Van Dooremolen, W. and Bouma, J., 1988. (Co-) kriging point data on moisture deficit. Soil Sci. Soc. Am. J. In press.

Van der Sluys, P. and De Gruijter, J.J., 1985. Water-table classes: a method used to indicate seasonal fluctuation and duration of water tables on Dutch soil maps. Agric. Water Manage., 10(2): 109-125.

Vauclin, M., Vieira, S.R., Vachaud, G. and Nielsen, D.R., 1983. The use of cokriging with limited field soil observations. Soil Sci. Soc. Am. J., 47: 175-184.

Webster, R., 1985. Quantitative spatial analysis of soil in the field. In: Advances in Soil Science, Vol. 3. Springer-Verlag, New York, N.Y.

Wösten, J.H.M., Bouma, J. and Stoffelsen, G.H., 1985. Use of soil survey data for regional soil water simulation models. Soil Sci. Soc. Am. J., 49: 1238-1244.

Wösten, J.H.M., Bannink, M.H. and Bouma, J., 1987. Land evaluation at different scales: you pay for what you get. Soil Survey and Land Evaluation, 7: 13-24.

Yates, S.R. and Warrick, A.W., 1987. Estimating soil water content using Cokriging. Soil Sci. Soc. Am. J., 51: 23-30. 